\title{
Developments in organic solid-liquid phase change materials and their applications in thermal energy storage
}

\author{
R.K. Sharma ${ }^{\text {a }}$, P. Ganesan ${ }^{\text {a,*, }}$, V.V. Tyagi ${ }^{\text {b }}$, H.S.C. Metselaar ${ }^{\text {a }}$, S.C. Sandaran ${ }^{c}$ \\ a Department of Mechanical Engineering, Faculty of Engineering, University of Malaya, 50603 Kuala Lumpur, Malaysia \\ ${ }^{\mathrm{b}}$ DST Centre for Policy Research, B.B.A. University (Central University), Rai Bareilly Road, Lucknow, UP, India \\ ${ }^{\text {c } U n i v e r s i t y ~ T e c h n o l o g y ~ M a l a y s i a, ~ J o h o r ~ B a h r u, ~ M a l a y s i a ~}$
}

\section{A R T I C L E I N F O}

\section{Article history:}

Received 4 December 2014

Accepted 29 January 2015

Available online 27 February 2015

\section{Keywords:}

Thermal energy storage

Latent heat

Organic phase change materials

Encapsulation

Thermal conductivity enhancement

\begin{abstract}
A B S T R A C T
Thermal energy storage as sensible or latent heat is an efficient way to conserve the waste heat and excess energy available such as solar radiation. Storage of latent heat using organic phase change materials (PCMs) offers greater energy storage density over a marginal melting and freezing temperature difference in comparison to inorganic materials. These favorable characteristics of organic PCMs make them suitable in a wide range of applications. These materials and their eutectic mixtures have been successfully tested and implemented in many domestic and commercial applications such as, building, electronic devices, refrigeration and air-conditioning, solar air/water heating, textiles, automobiles, food, and space industries.

This review focuses on three aspects: the materials, encapsulation and applications of organic PCMs, and provides an insight on the recent developments in applications of these materials. Organic PCMs have inherent characteristic of low thermal conductivity $(0.15-0.35 \mathrm{~W} / \mathrm{m} \mathrm{K})$, hence, a larger surface area is required to enhance the heat transfer rate. Therefore, attention is also given to the thermal conductivity enhancement of the materials, which helps to keep the area of the system to a minimum. Besides, various available techniques for material characterization have also been discussed. It has been found that a wide range of the applications of organic PCMs in buildings and other low and medium temperature solar energy applications are in abundant use but these materials are not yet popular among space applications and virtual data storage media. In addition, it has also been observed that because of the low melting point of organic PCMs, they have not yet been explored for high temperature applications such as in power plants.
\end{abstract}

(c) 2015 Elsevier Ltd. All rights reserved.

\footnotetext{
Abbreviations: ASHRAE, American Society of Heating, Refrigeration and AirConditioning Engineers; CA, capric acid; CNF, carbon nanofiber; CNT, carbon nanotube; CSP, concentrated solar power; DSC, differential scanning calorimeter; DTA, differential thermal analysis; EG, expanded graphite; ETC, evacuated tube DTA, differential thermal analysis; EG, expanded graphite; ETC, evacuated tube
collector; FESEM, field emission scanning electron microscope; FT-IR, Fourier collector; FESEM, field emission scanning electron microscope; FT-IR, Fourier
transformed infrared; GA, genetic algorithm; GNF, graphite nanofiber; GNP, graphite nano particles; HDPE, high density polyethylene; HRHE, heat recovery heat exchanger; HP, horse power; HSU, heat storage unit; IR, infrared; LA, lauric acid; LPE, low density polyethylene; LHTES, latent heat thermal energy storage; MA, myristic acid; MEPCM, microencapsulated phase change material; MMA, methyl methacrylate; MP, methyl palmitate; M.P., melting point; MS, methyl stearate: NG, nano graphite: PA, palmitic acid: $\mathrm{PCL}$, poly( $\varepsilon$-caprolactone): $\mathrm{PCM}$, phase phase change materials; $P E G$, poly (ethylene gly PMMA, poly methyl methacrylate; PNHMPA, poly(N-hydroxymethyl acrylamide); SDD, particle size polyvinyl pyrrolidone; PW, paraffin wax; RT, rubitherm; SA, stearic acid; SEM, scanning electron microscope; St, styrene; TGA, thermogravimetry analysis; TEM, transmission electron microscope; TES, thermal energy storage; TRNSYS, transient system simulation tool; USD, United States Dollar.

* Corresponding author. Tel.: +60 3 79675204/7670 (0); fax: +60 $379674579(0)$.

E-mail address: poo_ganesan@um.edu.my (P. Ganesan).

http://dx.doi.org/10.1016/j.enconman.2015.01.084 0196-8904/@ 2015 Elsevier Ltd. All rights reserved.

\section{Introduction}

Thermal energy storage (TES) using phase change materials PCM) have been a key area of research in the last three decades and more, and became an important aspect after the 1973-74 energy crisis. Depletion of the fossil fuels and increase in the energy demand has increased the gap between energy demand and its supply. Excess energy stored in a suitable form has been able to bridge this energy demand/supply gap significantly. TES can be used for either short term or long-term storage. If the energy is stored for a few hours, it is termed as short term storage and is essential in many industrial and domestic applications; while if energy is stored for a month or more, it is generally considered as a long term storage device which may also be required in some applications. Thermal energy storage plays a very important role when energy demand and supply are not equal. Excess energy 
available in the off peak time can be stored in TES devices for later use e.g. solar energy is available only in sunshine hours, thus, the excess heat may be stored in the day time and used later in the night hours. Energy storage helps in the saving of expensive fuels and reduces the wastage of energy and capital cost which leads to a cost effective system [1]. TES devices are majorly categorized as sensible heat storage and latent heat storage (LHS) devices. Although the most commonly used device in industrial applications for thermal energy storage, is the sensible heat storage bu the latent heat thermal energy storage (LHTES) devices have attracted a wide range of industrial and domestic applications and will be discussed in the later sections of this paper. LHTES provides large energy storage density with a smaller temperature change when compared to sensible heat storage devices [2,3]. Previous studies have shown that PCM has the capability to store about 3-4 times more heat per volume than is stored as sensible heat in the temperature increment of $20^{\circ} \mathrm{C}$ [4]. However, LHTES devices confront the difficulties that arise when the latent heat method is applied. This is due to the low thermal conductivity, change in density, stability of thermal properties and subcooling of PCMs.

There are a large number of review articles on the phase change materials such as Zalba et al. [5], Farid et al. [6], Tyagi and Buddhi [7], Sharma et al. [1], Cabeza et al. [10], Liu et al. [11], Tatsidjodoung et al. [12], Nkwetta and Haghighat [13], Pielichowska and Pielichowski [14] and ample information on organic PCMs are available in the literature, however, in a scattered manner. So far, most of the review articles have focused on general classifications of the PCMs and have presented their applications irrespective of their organic/inorganic nature. Organic PCMs are a very important class of materials because of their unique thermal properties such as congruent melting and narrow melting/freezing temperature range. These properties make them suitable for many applications in solar energy storage, textiles, and cooling of electronic devices. Organic PCMs are the most suitable materials for cooling/heating of building. Sarier and Onder [15] presented a review of organic PCMs suitability for textile industries. To the best of our knowledge, no review article has been made available which summarizes the classifications, thermal properties and applications of organic PCMs. Therefore, a review is required, which gives a deeper insight to organic PCMs and their applications. This pape reviews the present state of the art of the organic PCMs for thermal energy storage and provides insights into the efforts that have been made to develop new organic PCMs, showing enhanced therma performance. Attention is also given to the encapsulation methods and thermal conductivity enhancements. Use of organic PCMs in domestic and industrial applications such as in buildings, electronic devices, refrigeration, solar energy, textile, automobiles and food industry are broadly discussed.

\section{Phase change materials}

The PCMs are latent heat storage materials that have high heat of fusion, high thermal energy storage densities compared to sensible heat storage materials and absorb and release heat at a constant temperature when undergoing a phase change process (e.g. solid-liquid). The storage capacity of LHTES devices is given by [16]:

$Q=\int_{T_{i}}^{T_{m}} m C_{p} d T+m a_{m} \Delta h_{m}+\int_{T_{m}}^{T_{f}} m C_{p} d T$

$Q=m\left[C_{s p}\left(T_{m}-T_{i}\right)+a_{m} \Delta h_{m}+C_{l p}\left(T_{f}-T_{m}\right)\right]$ where $Q$ is the storage capacity, $C_{p}$ specific heat, $T_{i}, T_{m}$, and $T_{f}$ are initial, melting and freezing temperature, and $h$ is the enthalpy.

\subsection{Classification of PCMs}

Phase change materials are majorly classified as organic, inorganic, and eutectic and a comprehensive classification was given by Abhat [17] and shown in Fig. 1. Based on the melting/freezing temperature and latent heat of fusion, a large number of organic and inorganic materials can be treated as PCM. Even though, their melting/freezing temperature lies in the operating range, many of the PCMs do not satisfy the criteria required for an adequate thermal energy storage device because no single material can have all the properties required for TES. Therefore, the available materials are to be used and their thermo physical properties are to be improvised by making suitable changes in systems design or by using external agents. For example, the thermal conductivity of $\mathrm{PCM}$ can be increased by dispersion of metallic nanoparticle in the PCM or by inserting metallic fins in the systems design and supercooling can be suppressed by using a nucleating agent in the PCM.

Organic PCMs such as paraffin wax consist of straight $n$-alkanes chain $\left(\mathrm{CH}_{3}-\left(\mathrm{CH}_{2}\right)-\mathrm{CH}_{3}\right)$ and fatty acids that are made up of straight chain hydrocarbons and are relatively expensive and possess combustible nature. Organic materials possess the capability of congruent melting without phase separation. These compounds are available in a wide range of melting points [19]. Paraffin is safe reliable, predictable, inexpensive, non-corrosive and chemically inert and stable below $500{ }^{\circ} \mathrm{C}$ but possesses extremely low thermal conductivity $(0.1-0.3 \mathrm{~W} / \mathrm{m} \mathrm{K})$ and is not suitable for encapsulation in plastic containers. Organic PCMs will be discussed in detail in the later sections of this paper.

Inorganic materials are generally hydrated salts and metallic and have a large number of applications in solar energy $[20,21]$ As PCM, these materials are capable of maintaining the heat of fusion $\left(\sim 350 \mathrm{MJ} / \mathrm{m}^{3}\right)$ even after a large number of cycles and relatively higher thermal conductivity $\left(\sim 0.5 \mathrm{~W} / \mathrm{m}{ }^{\circ} \mathrm{C}\right)$, but they melt incongruently. One of the cheapest inorganic materials which is suitable to be used as thermal energy storage is Glauber salt $\left(\mathrm{Na}_{2} \mathrm{SO}_{4} \cdot \mathrm{H}_{2} \mathrm{O}\right)$, which contains $44 \% \mathrm{Na}_{2} \mathrm{SO}_{4}$ and $56 \% \mathrm{H}_{2} \mathrm{O}$ in weight and was studied by Telkes [22]. This salt has high latent heat $\left(254 \mathrm{~kJ} / \mathrm{kg}\right.$ ) and melting point of about $32.4^{\circ} \mathrm{C}$ but it is highly prone to phase segregation and subcooling. The corrosion of salt on metal

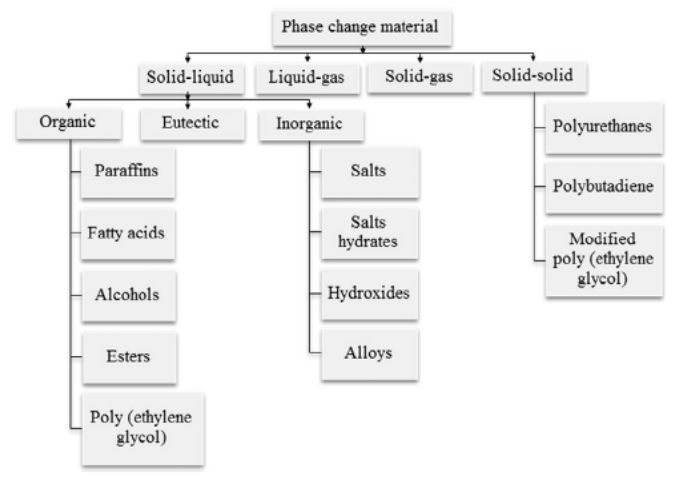

Fig. 1. Classifications of phase change materials $[1,5,17,18]$. 
container is also a concern [23]. The use of thickening agents e.g. Bentonite clay and nucleating agent e.g. Borax help to overcome the subcooling but they reduce the heat transfer rate by lowering the thermal conductivity. Generally, most of the salt hydrates encounter the same problem. An extensive review of hydrated salts was presented in chapter 1 of Lane [16] and Sharma et al. [24].

The eutectic is a composition of two or more components such as organic-organic, organic-inorganic, inorganic-inorganic and each of them change their phase congruently and form a mixture of component crystal during crystallization [25]. Eutectics generally melt and freeze congruently and leave no chances of separation of components [1].

\subsection{Thermo-physical properties}

Since thermo-physical properties of PCMs vary from one manufacturer to another, any of the available PCM cannot be simply used for designing an effective thermal energy storage device [26]. The PCM to be used as thermal storage system should possess the following thermal, physical, chemical, and economic properties [1,17,27-29]:

Thermal properties:

- Suitable phase change temperature.

- High specific heat.

- High latent heat.

- High thermal conductivity in both phase liquid and solid.

The operating temperature of heating or cooling should be matched with the phase change temperature of the PCM to be selected for energy storage. High specific heat provides the additional sensible heat storage. High latent heat is desirable to store the large amount of energy in a small volume of PCM i.e. to minimize the physical size of thermal energy storage. Thermal conductivity should be high in order to minimize the temperature gradient required for the melting and freezing of PCM.

Physical properties:

- High density.

- No or little subcooling during freezing.

- Low vapor pressure.

- Small volume change.

High density materials require relatively small storage containers and little subcooling avoid the temperature range required for freezing or melting of the PCM and give a single value of phase change temperature i.e. high nucleation rate. Low vapor pressure and small volume change in the PCM help to reduce the complexity of geometry of the container.

Chemical properties:

- Prolonged chemical stability.

- Compatible with capsule material.

- Non-toxic, non-flammable, and non-explosive.

Continuous freezing and melting cycles may hamper the chemical composition of the PCM so it is highly desirable that the material maintains its chemical stability over a long period of time. The PCM is to be encapsulated so it is not expected to have any kind of undesirable reaction to construction materials and from at safety point of view, it should be non-toxic, non-flammable, and nonexplosive.

Economic properties:

- Abundantly available.

- Inexpensive.
Inexpensive and easy availability of PCMs is a highly desirable characteristic.

\subsection{Encapsulation of PCMs}

Encapsulation is the technique used to hold the material in a sealed container of certain volume in order to achieve the following goals:

- To avoid direct contact between the PCM and environment which may be harmful for the environment or change the composition of the PCM.

- To prevent the leakage of the PCM when it is in a liquid state. - To increase the heat transfer area.

Encapsulation of PCMs has significantly received the attention of researchers in the last 20 years or more and different capsule materials and their compatibility with PCM along with the different geometries of encapsulation was discussed by Lane [20]. Encapsulation can be done in two possible ways, micro and macro encapsulations $[19,30]$. Microencapsulation is a technique in which a large number of PCM particles of 1-1000 $\mu$ m diameter are enclosed in a solid shell and then arranged in a continuous matrix [31]. Microencapsulation has widely found its application in textiles [32-35], cosmetics [36,37], pharmaceuticals [38-40], and buildings [41-43]. This encapsulation system suffers from low heat transfer rates due to the low thermal conductivity of the matrix materials and the chances of subcooling are higher. Another reason for this low heat transfer rate is the rigidity of the matrix that prevents the convective currents and forces all heat transfer to occur only by conduction [27]. Microencapsulation requires skills to be done and it is a relatively expensive process. Microencapsulated phase change materials (MEPCMs) are expected to possess some certain characteristics such as required morphology, uniform diameter, thermal stability, shell mechanical strength, and penetration abilities [44]. MEPCMs are in the form of pouches, tubes, sphere, panels or other receptacles and can be used directly as heat exchangers or can be incorporated into building products. Alkan et al. [45] in their literature survey indicates that urea-formaldehyde (UF) resin, melamine-formaldehyde (MF) resin and polyurethanes (PU) are the most appropriate microcapsule shell material. Macro encapsulation is very commonly used because of its availability in various shapes and sizes. This is mainly used to hold the liquid PCM and to prevent changes in its composition due to contact with the environment. It also adds the mechanical stability to a system if the container is sufficiently rigid. There are numerous techniques adopted for microencapsulation such as coacervation [46-49], suspension [33,50,51], emulsion [52-54], condensation [55-58], and polyaddition polymerization [50,59,60].

In the coacervation method, more than one colloid is involved and it results from the neutralization of the oppositely charged colloids in an aqueous solution [61]. Suspension polymerization is a technique for encapsulation in which the PCM as core is filled in a polymer shell. A monomer is dispersed in the form of droplets in an appropriate medium and polymerization is initiated. Sánchez-Silva et al. [62] studied the microencapsulation of various PCMs by suspension copolymerization of styrene (St) and methyl methacrylate (MMA). They investigated the influence of the monomers/paraffin on the encapsulation process and thermo-physical properties. The ratio of MMA and St is reported to influence the polymerization rate and affect the time at which the identity point is reached. In a recent study [63], the effect of polymeric shell dry glass transition temperature and the reaction temperature on the microencapsulated paraffin prepared by suspension-like copolymerization technique was studied. It was reported that, 
when the shell dry glass transition temperature was at least $10^{\circ} \mathrm{C}$ above the reaction temperature, the irregular shape particles were observed, while, when the transition temperature was between $10-20{ }^{\circ} \mathrm{C}$, uniform and spherical particles were obtained. PMMA microcapsules containing docosane [45], n-octacosane [52], and $n$-eicosane [64] were prepared by emulsion polymerization and their thermal properties were evaluated and in all three studies, the thermal cycle test showed a good chemical stability. The results showed that the PMMA microcapsules consisted of $28 \%$ docusate, 43\% n-octacosane, and 35\% n-eicosane respectively and the best thermo-physical properties as a PCM was shown by the $43 \%$ n-octacosane. Rao et al. [65] encapsulated the n-docosane in the melamine resin shell by polycondensation technique. Melted paraffin is emulsified in water using water-soluble mixers to achieve the desired size and stability and then melamine resin is added to the solution. Addition of acid initiates the polycondensation. MEPCM with a core mass fraction of $60 \%$ showed a latent heat of $150 \mathrm{~kJ} / \mathrm{kg}$ in the DSC test and the thermal cycling test found this encapsulation process thermally and chemically stable and reliable. Recently, Zhang et al. prepared the MEPCM by encapsulating $n$-octadecane as a core in silica shells at various $\mathrm{pH}$ values using the interfacial polycondensation technique [66]. SEM image showed the strong dependence of morphology and microstructure on the acidity of the reaction solution. An optimum sample was achieved at pH value of 2.89 and particle size of $17 \mu \mathrm{m}$.

Technological advancements have made it possible to encapsulate PCMs at nanoscale as well. Sukhorukov et al. [67] have shown that nanocapsules are more stable than microcapsules. They found that deformation in the $10 \mathrm{~nm}$ capsule is significantly lesser than that in the $10 \mu \mathrm{m}$ for the same force exerted on the capsule. Unlik the microcapsules, in the nanoencapsulation technique the core material is kept in the shell during freeze/thaw cycle [68]. The $n$ tetradecane was encapsulated at nano level of diameter as $100 \mathrm{~nm}$ and urea and formaldehyde were used as the shell polymerization materials. The experiments were then conducted to test the thermal reliability of the nanoencapsulated PCM in Ref. [68]. In this study, at the stirring rate of $200 \mathrm{rpm}$ and a pH value of 3-4, the prepolymer solution was added drop by drop into oil/water emulsion. The stirring rate was increased to $500 \mathrm{rpm}$ and maintained for $4 \mathrm{~h}$, then the urea-formaldehyde polymer network was formed and the oil/water interface, the PCM was then encapsulated. A the mass content of $60 \%$ PCM, differential scanning calorimeter (DSC) results indicated the high latent heat $134.61 \mathrm{~kJ} / \mathrm{kg}$. Very recently, Tumirah et al. [69] prepared the n-octadecane filled nanocapsules and carried out the thermo-physical characterization for TES. The melting and freezing point were reported as $29.5^{\circ} \mathrm{C}$ and $24.6{ }^{\circ} \mathrm{C}$ respectively when tested by DSC. The influence of shell material St/MMA on the encapsulation efficiency was evaluated and the nanocapsules showed good thermal properties for the tested 360 thermal cycles.

The effects of capsule geometry have also been reported in previous studies and found that the geometry can be a significan parameter to improve the thermal performance of PCMs. Regula geometries like square [70-73], cylindrical [74-78], and spherica [79-83] have been extensively tested but the studies using irregular geometries such as triangular and trapezoidal are scarce. Duggirala et al. [84] investigated the solidification of binary mixture of various concentrations of ammonia-water filled in trapezoidal cavity. However, this study does not explicitly investigate the effect of the trapezoidal cavity on the solidification rate and is not based on solidification/melting of NEPCM. Recently, Sharm et al. [85] numerically investigated the effect of trapezoidal cavity on solidification of copper-water nanofluid. They performed the CFD simulation for various aspect ratios and calculated the solidification time for various initial fluid temperatures, cold wall temperatures, and Grashof number. This shape of cavity was found to be a controlling parameter for the total solidification time of NEPCM.

Organic phase change materials show negligible or no supercooling during the freezing process and provide congruent melting while supercooling is one of the major problems in the inorganic materials. In addition, comparatively they are more chemically stable, non-corrosive, possess high latent heat and low vapor pressure. Unlike the inorganic materials, most of the organic PCMs possess a sharp or narrower range of phase change temperature. Inorganic materials have high thermal conductivity and are comparatively less expensive but suffer of decomposition and require nucleating agents for crystallization. Encapsulation is essential for PCMs to avoid their interaction with the external environment, which helps to curb the chemical reactions to occur and to prevent the leakage when they are in the molten stage. The encapsulation types such as the macro, micro and nano encapsulation and the techniques to encapsulate them play a very important role in enhancing the heat transfer rate and their durability. Organic PCMs show a good mixing property with construction materials and provide high energy density compared to inorganic materials. Among all the methods available for microencapsulation, In situ polymerization has been found as the most suitable technique.

\section{Organic PCMs}

Organic PCMs provide congruent melting and are further classified as paraffins and non-paraffins. These materials provide the congruent melting without phase segregation over the large number of melting/freezing cycles at the cost of degrading latent heat of fusion and do not suffer from supercooling. Hale [86] in 1971, provided the data related to the material properties of more than 500 PCMs required by thermal design engineers to build efficient thermal energy storage devices. This was followed by numerous studies that focused on organic PCMs. Paraffin waxes, poly(ethylene glycol)s, fatty acids and their derivatives are the major classification of organic PCMs, which undergo a solid-liquid phase transition during heating and subsequent cooling. Polyalcohols and polyethylene are the other groups of organic PCMs, which undergo a solid-solid phase transition. Such a kind of phase transition occurs at a fix temperature by absorbing/releasing large amounts of the latent heat. A detailed list of organic PCM candidates can be found in the literature $[5,6,10,17,87,88]$. Apart from the many listed advantages of organic PCMS, their major drawbacks are low thermal conductivity which curb the charging/discharging rate, super cooling effect in cooling cycles, and leakage of PCM in the containers [89-91].

\subsection{Paraffins}

Paraffin or paraffin wax is a mixture of straight chain $n$-alkanes which is represented by the chemical formula $\mathrm{C}_{n} \mathrm{H}_{2 n+2}$, where $20 \leqslant n \leqslant 40$. Depending on the chain length of the alkane, paraffins may be even-chained ( $n$-paraffin) or odd-chained (iso-paraffin) [17]. Studies conducted over recent years on paraffins are summarized in Table 1. The molecular chain of paraffin wax involves large amount of latent heat during the crystallization/fusion. The melting temperature of these compounds increases with increase of number of alkane chains in the molecules [92] as seen in Table 1. This increment in the melting temperature is because of the elevated induced dipole attraction between $n$-alkane chains [15] e.g. the melting point of $\mathrm{C} 14$ is $4.5^{\circ} \mathrm{C}$ and that of $\mathrm{C} 18$ is $28^{\circ} \mathrm{C}$. Many previous studies [93-100] have shown that paraffin waxes are capable to absorb, store, and release a great amount of heat over a large number of phase change cycles. They are excellent materials fo energy storage, particularly in the buildings with a heat capacity 
Table 1

Thermo-physical properties of some paraffins, paraffin waxes, and its blends used as latent heat storage.

\begin{tabular}{|c|c|c|c|c|c|c|}
\hline Compound & $T_{m}\left({ }^{\circ} \mathrm{C}\right)$ & $H_{f}(\mathrm{~kJ} / \mathrm{kg})$ & $C_{p}(\mathrm{~kJ} / \mathrm{kg} \mathrm{K})$ & $k(\mathrm{~W} / \mathrm{m} \mathrm{K})$ & $\rho\left(\mathrm{kg} / \mathrm{m}^{3}\right)$ & Ref. \\
\hline Decane & -29.65 & 202 & - & - & $726(1)$ & [92] \\
\hline Undecane & -25.6 & 177 & - & - & 737 (l) & [92] \\
\hline Dodecane & -9.6 & 216 & - & - & 745 (l) & [92] \\
\hline Tridecane & -5.4 & 196 & $2.21(1)$ & - & $753(1)$ & [92] \\
\hline Paraffin C14 & 4.5 & 165 & - & - & - & [17] \\
\hline Tetradecane & 5.5 & 227 & $2.07(\mathrm{~s})$ & 0.15 & $825(s)$ & [92] \\
\hline Paraffin C15-C16 & 8 & 153 & $2.2(\mathrm{~s})$ & - & - & [17] \\
\hline Paraffin C16-C18 & $20-22$ & 152 & - & - & - & [7] \\
\hline \multirow[t]{2}{*}{ Paraffin $\mathrm{C} 13-\mathrm{C} 14$} & $22-24$ & 189 & 2.1 & 0.21 & $790(1)$ & [7] \\
\hline & & & & & $900(s)$ & [4] \\
\hline Paraffin C18 & 28 & 244 & 2.16 & 0.15 & 814 & [17] \\
\hline Nonadecane & 32 & 222 & - & - & 785 & [3] \\
\hline Eicosane & 36.6 & 247 & & & 788 & [3] \\
\hline Heneicozane & 40.2 & 213 & - & - & 791 & [3] \\
\hline \multirow[t]{2}{*}{ Paraffin $\mathrm{C} 20-\mathrm{C} 33$} & $48-50$ & 189 & 2.1 & 0.21 & $769(1)$ & [17] \\
\hline & & & & & $912(\mathrm{~s})$ & \\
\hline \multirow[t]{2}{*}{ Paraffin C22-45 } & $58-60$ & 189 & 2.1 & 0.21 & 795 (IC) & [17] \\
\hline & & & & & $920(\mathrm{~s})$ & \\
\hline 1-Tetradecanol & 38 & 205 & - & - & 825 & [102] \\
\hline Paraffin C23-C45 & $62-64$ & 189 & 2.1 & 0.21 & 0.915 & [17] \\
\hline \multirow[t]{2}{*}{ Paraffin wax } & 64 & 173.6 & - & $0.167(\mathrm{l})$ & $790(1)$ & [103] \\
\hline & & 266.0 & & $0.346(\mathrm{~s})$ & $916(s)$ & [21] \\
\hline \multirow[t]{2}{*}{ Paraffin C21-C50 } & $66-68$ & 189 & - & 0.21 & $830(1)$ & [17] \\
\hline & & & & & $930(\mathrm{~s})$ & \\
\hline \multirow{2}{*}{ Biphenyl } & 71 & 119.2 & - & - & $994(1)$ & [103] \\
\hline & & & & & $1166(s)$ & [21] \\
\hline Propionamide & 79 & 168.2 & - & - & - & [103] \\
\hline \multirow[t]{3}{*}{ Napthelene } & 80 & 147.7 & 2.8 & $0.132(1)$ & $976(1)$ & [103] \\
\hline & & & & $0.341(\mathrm{~s})$ & $1145(s)$ & [104] \\
\hline & & & & $0.310(\mathrm{~s})$ & & [21] \\
\hline Tetradecane + octadecane & -4.02 to 2.1 & 227.52 & - & - & - & [8] \\
\hline $91.67 \%$ Tetradecane $+8.33 \%$ hexadecane & 1.70 & 156.20 & - & - & - & [10] \\
\hline Tetradecane + docos ane & $1.5-5.6$ & 234.33 & - & - & - & [10] \\
\hline Paraffin blend $(n=14-16)$ & $5-6$ & 152 & - & - & $783(s)$ & [105] \\
\hline Paraffin blend $(n=15-16)$ & 8 & $147-153$ & - & - & 751.6 & [105] \\
\hline Paraffin blend ( $n=16-18)$ & $20-22$ & 152 & - & - & - & [105] \\
\hline Octadecane + heneicosane & $25.8-26$ & 193.93 & - & - & - & [10] \\
\hline Octadecane + docosane & $25.5-27$ & 203.80 & - & - & - & [10] \\
\hline
\end{tabular}

of $2.14-2.4 \mathrm{~kJ} / \mathrm{kg} \mathrm{K}$, and latent heat of $200-220 \mathrm{~kJ} / \mathrm{kg}$. Paraffins display no phase segregation even after many phase transition cycles and exhibit many favorable characteristics as PCMs such as they are chemically inert, non-corrosive, colorless, durable, inexpensive, available abundantly, ecologically harmless and nontoxic $[16,17,26,101]$. On the contrary, Lane [16] reported that paraffin shows slow oxidation when exposed to oxygen, therefore, it requires leak-proof containers. They are generally compatible with all metallic containers but on the other hand they make some plastic containers soften [16]. Paraffins possess low thermal conductivity in the liquid state; therefore, high latent heat is required during the freezing cycle. This property of the paraffin can be improved by using metal fillers and other techniques in the base materials, and this has been discussed in detail in Section 4.

\subsection{Fatty acids}

Non-paraffins are generally found in the form of acid and represented by the formula $\mathrm{CH}_{3}\left(\mathrm{CH}_{2}\right)_{2 n} \mathrm{COOH}$ [88]. The fatty acids are basically derived from vegetable and animal sources which ensure nonpolluting source of supply [106] and are divided into six groups: caprylic, capric, lauric, myristic, palmitic and stearic [17]. The individual material in this category has its own properties unlike paraffins which have very similar properties [1]. When compared with paraffins, these materials show excellent phase change (solid-liquid) properties but are about three times more expensive than paraffins [26]. An extensive survey of organic materials was done by Abhat et al. [107] and Buddhi and Sawhney [108] and the number of esters, fatty acids, alcohol's and glycol's were identified to be suitable as latent heat storage. These materials are highly flammable and should avoid exposure to high temperature, flames and oxidizing agents. Fatty acids and palmitoleic acids, which have a low melting point, are the most common among others in the category. The melting temperatures of fatty acids vary from -5 to $70^{\circ} \mathrm{C}$ and the latent heat from 45 to $210 \mathrm{~kJ} / \mathrm{kg}$ [8]. These materials have the capability to be retained in the shape of host material due to their high surface tension of $2-3 \times 10^{-4} \mathrm{~N} / \mathrm{cm}$. A great insight of fatty acids was recently presented by Yuan et al. 109]. Some of the fatty acids investigated in the past are presented in Table 2. PCMs based on fatty acids can be categorized as follows [110]:

1. Naturally occurring triglycerides.

2. Hydrates of acids of triglycerides and their mixtures.

3. Esters of the fatty acids of naturally occurring triglycerides.

4. Refined/synthesized triglyceride products produced by a combination of fractionation and transesterification processes.

5. Synthesized triglyceride products using hydrogenation (or dehydrogenation) and fractionation.

6. Synthesized triglyceride products using cis-trans isomerization and fractionation.

7. Synthesized fatty acid derivatives that have the desired freezing point temperatures.

8. Refined fatty acid hydrates that have the desired freezing point temperatures. 
Table 2

\begin{tabular}{|c|c|c|c|c|c|c|}
\hline Acid & $T_{m}\left({ }^{\circ} \mathrm{C}\right)$ & $H_{f}(\mathrm{~kJ} / \mathrm{kg})$ & $C_{p}(\mathrm{~kJ} / \mathrm{kg} \mathrm{K})$ & $k(\mathrm{~W} / \mathrm{m} \mathrm{K})$ & $\rho\left(\mathrm{kg} / \mathrm{m}^{3}\right)$ & Ref. \\
\hline Enanthic & -7.4 & 107 & - & - & - & [119] \\
\hline Butyric & -5.6 & 126 & - & - & - & [111] \\
\hline Caproic & -3 & 131 & - & - & - & [111] \\
\hline Propyl palmiate & 10 & 186 & - & - & - & [102] \\
\hline Pelargonic & 12.3 & 127 & - & - & - & {$[140]$} \\
\hline Isopropyl stearate & $14-18$ & $140-142$ & - & - & - & [120] \\
\hline \multirow[t]{2}{*}{ Caprylic } & 16 & 148.5 & - & $0.149(\mathrm{l})$ & $862(1)$ & [17] \\
\hline & 16.5 & 149 & & $0.148(1)$ & $\begin{array}{l}1033(\mathrm{~s}) \\
981(\mathrm{~s})\end{array}$ & $\begin{array}{l}{[103]} \\
{[21]}\end{array}$ \\
\hline \multirow[t]{2}{*}{ Butyl stearate } & 19 & 140 & - & - & - & [102] \\
\hline & & $123-200$ & & & & [120] \\
\hline Dimethyl sabacate & 21 & $120-135$ & - & - & - & [120] \\
\hline Undecylenic & 24.6 & 141 & - & - & - & [121] \\
\hline Vinyl stearate & $27-29$ & 122 & - & - & - & [120] \\
\hline Undecylic & 28.4 & 139 & - & - & - & [140] \\
\hline \multirow{2}{*}{ Capric } & 31.5 & 153 & - & $0.149(\mathrm{l})$ & $886(1)$ & [17] \\
\hline & 32 & 152.7 & & $0.153(1)$ & $878(1)$ & $\begin{array}{l}{[103]} \\
{[21]}\end{array}$ \\
\hline Tridecylic & 41.8 & 157 & - & - & - & [140] \\
\hline Methyl- 12 hydroxy-stearate & $42-43$ & $120-126$ & - & - & - & {$[120]$} \\
\hline \multirow[t]{3}{*}{ Lauric acid } & $42-44$ & 178 & 1.6 & $0.147(\mathrm{l})$ & $870(1)$ & [17] \\
\hline & 44 & 177.4 & & & $862(1)$ & [103] \\
\hline & & & & & $1007(\mathrm{~s})$ & \\
\hline Elaidic & 47 & 218 & - & - & $851(\mathrm{l})$ & [86] \\
\hline \multirow[t]{3}{*}{ Myristic } & 54 & 187 & $1.6(\mathrm{~s})$ & - & 844 (1) & [17] \\
\hline & 58 & 186.6 & $2.7(\mathrm{l})$ & & $990(s)$ & [103] \\
\hline & $49-51$ & 204.5 & & & & [114] \\
\hline Pentadecanoic & $52-53$ & 178 & - & - & - & [1] \\
\hline Margaric & 60 & 172.2 & & & & \\
\hline \multirow[t]{3}{*}{ Palmitic } & 63 & 187 & - & 0.165 (l) & $874(1)$ & [17] \\
\hline & 61 & 203.4 & - & 0.159 (l) & $847(1)$ & [122] \\
\hline & 64 & 185.4 & - & $0.162(\mathrm{l})$ & 850 (l) & [117] \\
\hline \multirow[t]{4}{*}{ Stearic } & 70 & 203 & $2.35(1)$ & $0.172(1)$ & 941 (l) & [17] \\
\hline & 69 & 202.5 & & & $848(1)$ & [122] \\
\hline & $60-61$ & 186.5 & & & & [116] \\
\hline & 69.4 & 199 & & & & [86] \\
\hline Nonadecylic & 67 & 192 & & & & [15] \\
\hline Arachidic & 74 & 227 & - & - & - & [121] \\
\hline Heneicosylic & $73-74$ & 193 & & & & [15] \\
\hline Phenylacetic & 16.7 & 102 & & & & [1] \\
\hline Acetamide & 81 & 241 & - & - & - & [86] \\
\hline
\end{tabular}

9. Prepared mixtures produced by essentially any of the previous processing approaches with other chemicals (preferable cheap and nontoxic) to produce eutectic compositions with the desired freezing point temperature range.

Fatty acids possess the superior properties such as congruent melting, good chemical and thermal stabilities, nontoxicity, biodegradability, and melting temperature range suitable for many latent heat storage applications. They are also capable of thousands of thermal (melting/freezing) cycles without any notable degradation in thermal properties [106,111,112]. The fatty acids and their eutectic mixtures have been recently investigated extensively as possible phase change materials for low/medium energy storage applications such as solar energy storage and residential applications. Thermal properties of fatty acids such as capric, lauric, palmitic and stearic acids were evaluated by Feldman et al. [111 and they found that these materials are very promising to be used as PCMs in space heating applications. The melting point of these acids was measured between $30^{\circ} \mathrm{C}$ and $65^{\circ} \mathrm{C}$ and latent hea between $153 \mathrm{~kJ} / \mathrm{kg}$ and $182 \mathrm{~kJ} / \mathrm{kg}$. Feldman et al. [106,112,113] further investigated the behavior of fatty acids and their thermal stability as PCMs. The thermal performance of myristic acid was investigated by Sari and Kaygusuz [114] and they found that this acid shows better stability at low temperature. They also observed that this PCM is more effective when heat exchanger is in horizon- tal position. A. Sari et al. studied the thermal performance of stearic acid [116] and palmitic acid [117] as thermal energy storage. In their later study, A. Karaipekli et al. [118] tested the eutectic mixture of capric and stearic acid and found it as a potential material for low temperature solar energy in building applications. Detailed review on organic PCMs can be found in Rozanna et al. [110] and Sarier and Onder [15].

In order to improve the thermal performance and widen the application scope of organic PCMs, many researches have been preparing the eutectics of fatty acids and other PCMs. For a low temperature thermal energy storage, a mixture of capric and lauric acids was evaluated as possible phase change material by L. Shieli et al. [123]. Later Dimaano and Watanabe [124] in their research, mixed pentadecane in the capric-lauric mixture and found that $50 \%$ of pentadecane in the mixture provides the highest heat charged. The solid-liquid phase transition in lauric, palmitic, stearic acid and their binary systems was studied by Zhang et al. [125] and they found that thermal properties of $23 \%$ lauric-palmitic acid eutectic system remained stable after 100 heating-cooling cycles at $32.8^{\circ} \mathrm{C}$. Sari et al. [8] evaluated the thermal properties of lauric-stearic, myristic-palmitic, and palmitic-stearic acid and tested the thermal stability for 360 melting-freezing cycle and concluded that these materials can be effectively used for a one year period. Later Sari [9] studied the thermal performance of eutectic mixtures of lauric-myristic acid, lauric-palmitic acid, and myristic-stearic 
Table 3

\begin{tabular}{llll}
\multicolumn{4}{l}{ Thermo-physical properties of compound of fatty acids used as latent heat storage. } \\
\hline \multicolumn{1}{l}{ Compound (wt\%) } & $T_{m}\left({ }^{\circ} \mathrm{C}\right)$ & $H_{f}(\mathrm{~kJ} / \mathrm{kg})$ & Ref. \\
\hline CA-LA (90-10) & 13.3 & 142.2 & {$[27]$} \\
CA-LA (64-36) & 19.62 & 149.95 & {$[126]$} \\
CA-LA (65.1-34.9) & 19.67 & 126.56 & {$[123]$} \\
CA-LA (45-55) & $17-21$ & 143 & {$[9]$} \\
CA-LA (70-30) & 21.09 & 123.98 & {$[127]$} \\
CA-MA (70-30) & 21.79 & 123.62 & {$[127]$} \\
CA-LA (66.75-33.25) & 22.76 & 127.2 & {$[128]$} \\
CA-PA (76.5-23.5) & 23.12 & 156.44 & {$[126]$} \\
CA-SA (70-30) & 23.40 & 104.90 & {$[127]$} \\
$\mathrm{C}_{14} \mathrm{H}_{28} \mathrm{O}_{2}-\mathrm{C}_{10} \mathrm{H}_{20} \mathrm{O}_{2}(34-66)$ & 24 & 147.7 & {$[1]$} \\
CA-SA (83-17) & 24.68 & 178.69 & {$[126]$} \\
CA-SA (83-17) & 25.39 & 188.15 & {$[126]$} \\
CA-MA (78.39-21.61) & 26.02 & 155.2 & {$[128]$} \\
CA-PA (70-30) & 27.07 & 142.61 & {$[127]$} \\
CA-PA (89-11) & 28.71 & 141.4 & {$[128]$} \\
LA-MA (60-40) & $28.8-40.8$ & 172 & {$[9]$} \\
LA-MA-SA (55.8-32.8-11.4) & 29.29 & 140.9 & {$[129]$} \\
LA-MA-PA (55.24-29.75-15.02) & 31.14 & 142.6 & {$[130]$} \\
CA-SA (94.47-5.53) & 31.17 & 156.8 & {$[128]$} \\
LA-PA (65-35) & $32.8-37.1$ & 170.2 & {$[9]$} \\
LA-SA (60.3-39.7) & $33.8-47.6$ & 189.8 & {$[115]$} \\
MA-SA (50-50) & $35.2-51.8$ & 189.2 & {$[9]$} \\
LA-SA (75.1-24.9) & $36.9-37.6$ & 183.4 & {$[8]$} \\
MA-PA (50-50) & $39.1-45.4$ & 173.7 & {$[8]$} \\
MA-PA (50-50) & 47.91 & 153.12 & {$[125]$} \\
PA-SA (60-40) & $51.2-54.2$ & 183.7 & {$[8]$} \\
CA-LA (65-35) & 18 & 148 & {$[124]$} \\
CA-LA (45-55) & 21 & 143 & {$[102]$} \\
\hline
\end{tabular}

acid as PCM and found that these PCMs have good thermal stability for at least for four years. Subsequently Sari and Kaygusuz investigated the thermal behavior of the eutectic mixture of myristic acid and stearic acid that can be effectively used as PCMs in low temperature thermal energy storages. Some of the studies carried out on eutectic mixtures are shown in Table 3.

\subsection{Sugar alcohol}

Sugar alcohol, also known as polyalcohols are considered as medium temperature $\left(90-200^{\circ} \mathrm{C}\right)$ PCMs and have received less attention by researchers. Previous studies revealed that alcohols such as xylitol, erythritol, and mannitol possess a much higher value of latent heat than other materials in this family. Alcohols have been tested as potential phase change materials in the last four decades. Hormansdorfer [131] first proposed the use of polyalcohols as PCM but their phase change behavior was discussed by Talja and Roos [132], and Kaizawa et al. [133]. They observed that some polyalochols possess latent heat almost double than that of the other organic PCMs. Among sugar alcohols, erythritol has shown excellent suitability as a thermal energy storage material [134]. Its melting point is $20^{\circ} \mathrm{C}$ and latent heat of fusion is $339.8 \mathrm{~kJ} / \mathrm{kg}$. Shukla et al. [135] performed a thermal cycling test of erythritol and observed no degradation for the 75 thermal cycles and experienced a supercooling of $15^{\circ} \mathrm{C}$. At a certain temperature, they observed the phase separation in the liquid state. When compared to lower temperature organic PCMs, sugar alcohol exhibited much larger degree of super cooling which can hamper the efficiency of thermal energy storage and has been addressed in number of research articles [136-139]. These materials also undergo the $10-15 \%$ volume expansion during melting [133].

Solé et al. [140] tested sugar alcohols D-mannitol, myo-inositol, and galactitol as potential PCMs by thermal cycle test. It was found that for the chosen set of parameters, myo-inositol sustained well during the cycling test, however, FT-IR images show changes in chemical structure, which does not affect the thermal properties.
Some polymorphic changes were noticed when myo-inositol was analyzed between 50 and $260^{\circ} \mathrm{C}$ but they were found almost disappeared in the temperature range 150 to $260{ }^{\circ} \mathrm{C}$. Galactitol showed poor cycling stability and at 18 th cycle, its freezing temperature was measured as $60^{\circ} \mathrm{C}$, which was $102^{\circ} \mathrm{C}$ before starting the cycle test. D-Mannitol showed the reaction with oxygen in the atmosphere which leads to the non-stable materials with a lower thermal energy storage capacity.

Ali Memon et al. [141] developed a novel form stable alcohol based PCM by preparing a composite of lauryl alcohol and kaolin using vacuum impregnation method, Fig. 2(a). Simultaneous heating checked the exudation of this composite during impregnation process. Leakage testing was performed to check the maximum absorption ratio. The composite was placed in the oven at a certain temperature above the melting point for $30 \mathrm{~min}$. This composite was checked for thermal reliability by performing cycling test. An experimental set up, Fig. 2(b), which consist a test room, a $150 \mathrm{~W}$ infrared lamp (as heating source), a hollow PVC envelope, and the thermocouple, was designed and developed. Leakage test showed that the maximum $24 \%$ lauryl acid can be retained by this composite. DSC measured the melting point of this composite as $19.14{ }^{\circ} \mathrm{C}$, which is less than of the pure lauryl acid melting point of $25^{\circ} \mathrm{C}$ and latent heat of fusion of $48.08 \mathrm{~kJ} / \mathrm{kg}$, which is higher when compared to that of the lauryl acid $205.4 \mathrm{~kJ} / \mathrm{kg}$. Thermal cycling test revealed that after one month of complete cycling test, the melting point of composite dropped by $0.39{ }^{\circ} \mathrm{C}$ and latent heat of fusion was dropped by $0.7 \mathrm{~kJ} / \mathrm{kg}$.

\subsection{Esters}

Esters are derived from acids in which one hydroxyl $(-\mathrm{OH})$ group is replaced by one alkyl $(-0)$ group. Fatty acid esters show the solid-liquid transition over a narrow temperature range and they can form the eutectics without or little subcooling [14]. Many fatty acid esters are commercially available in large quantities for applications in polymer, cosmetics, smart clothing [106,142149]. Solid-liquid transition of five fatty acid esters: methyl stearate, methyl palmitate, cetyl stearate, cetyl palmitate and their eutectic mixtures (methyl stearate-methyl palmitate, methyl stearate-cetyl palmitate and methyl stearate-cetyl stearate) was studied by Nikolić et al. [143] using DSC. The prepared samples were tested for 50 thermal cycles in the temperature range -10 to $60{ }^{\circ} \mathrm{C}$. These cycles were repeated after having stored these samples for 18 months and no change in thermo-physical properties were measured. DSC results showed that up to $30 \%$ of esters can be absorbed in the building materials. Stearic acid esters were prepared, synthesized, characterized and their thermal properties were tested by Sari et al. [150]. These ester compounds were synthesized by reacting stearic acid with $n$-butyl alcohol, isopropyl alcohol and glycerol and characterized by Fourier transform infrared spectroscopy (FT-IR) and H Nuclear Magnetic Resonance (H NMR) techniques. FTIR images shows that in the range of 3200$3650 \mathrm{~cm}^{-1}$, the hydroxyl absorption peaks disappear which means all hydroxyl groups of alcohols have been transformed into ester bonds. DSC results showed that there was no residual stearic acid in the synthesized PCM. Prepared esters were tested for 200 thermal cycles and no degradation in thermal properties was observed after 100 cycles. High chain fatty acid esters of myristyl alcohol $[146,151]$ and 1-hexadecanol [147] were prepared and it was observed that these materials are suitable for low temperature thermal energy storage and possess superior thermal properties and reliability. An organic ester PCM was prepared by mixing silver nitrate into an organic PCM polyvinyl pyrrolidone (PVP) 4000 [152] and their thermal properties were evaluated experimentally. Addition of silver nanoparticle in the PCM showed only physical changes and no chemical changes were noticed. The thermal 

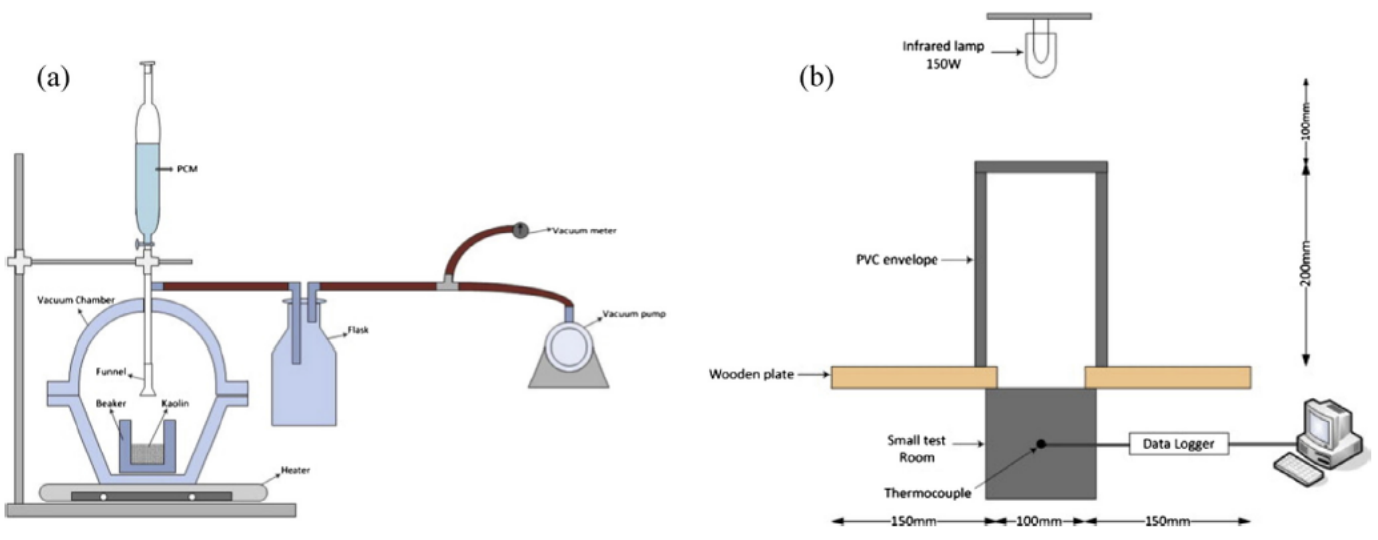

Fig. 2. (a) Vacuum impregnation method, (b) schematic of thermal performance test. Reprinted from [141] with permission from Elsevier.

conductivity of the ester was enhanced from 0.284 to $0.765 \mathrm{~W} /$ $\mathrm{m} \mathrm{K}$. The freezing and melting cycle was improved by $41-45.6 \%$ respectively. Aydin and Okutan [153] prepared a mixture of polyurethane (PU) rigid foam and myristyl myristate (PCM). The DSC analysis for this PU-PCM composite was carried out at $5{ }^{\circ} \mathrm{C} / \mathrm{min}$ heating and cooling rate for the determination of phase change temperature, enthalpy and total absorbed heat. The DSC results indicate that the total heat absorption capacity can be improved by up to $34 \%$, which represents the enhanced thermal energy storage capacity. Xu et al. [154] prepared the esters of fatty acids methyl palmitate (MP) and methyl stearate (MS) to meet the thermal requirement of a building $\left(25-40^{\circ} \mathrm{C}\right)$ and their thermal reliability were tested. When the mass ratio of MP/MS was 70/30, 60 $40,50 / 50$, and $40 / 60$, the DSC results showed two distinctive endothermic peaks. One of the peaks shows the melting point and the other one is at $17.33^{\circ} \mathrm{C}$, which indicates that these MP/ MS binary mixtures may from a compound with an incongruent melting point. The thermal cycling test shows that even after for 360 thermal cycles, the DSC results of binary mixture is the same as for the fresh mixture.

\subsection{Poly(ethylene glycol)s}

Polyethylene glycol (PEG) also known as polyoxyethylene (POE) or polyethylene oxide (PEO) is composed of dimethyl ether chains, $\mathrm{HO}-\mathrm{CH}_{2}-\left(\mathrm{CH}_{2}-\mathrm{O}-\mathrm{CH}_{2}-\right)_{n}-\mathrm{CH}_{2}-\mathrm{OH}$. Having the hydroxyl group at the end, they are soluble in water as well as in organic compounds. PEGs in various grades $(400,600,1000,3400,10,000,20,000$, $35,000,100,000$, and $1,000,000)[14]$ have been extensively investigated numerically and experimentally in the past and they are found to be chemically and thermally stable, nonflammable, nontoxic, non-corrosive and inexpensive [163-167]. As reported by Sarier and Onder [15], the melting point and latent heat of fusion increase with increasing molecular weight (MW), e.g. melting point of PEG (MW 400) is $3.2^{\circ} \mathrm{C}$ and latent heat $91.4 \mathrm{~kJ} / \mathrm{kg}$, PEG (MW 2000) is $51{ }^{\circ} \mathrm{C}$ and latent heat $181.4 \mathrm{~kJ} / \mathrm{kg}$, and PEG (MW 20,000 ) is $68.7^{\circ} \mathrm{C}$ and latent heat $187.8 \mathrm{~kJ} / \mathrm{kg}$. Ahmad et al. [168] experimentally and numerically investigated the thermal performance of a wallboard filled with PEG 600. The apparent heat capacity method was adopted to numerically simulate the phase change process in a vertical panel. A sinusoidal variation of the outdoor temperature (Eq. (3)) was considered in the numerical simulation, which represents the daily variation in the outside temperature. Simulations started with the investigation using paraffin in gypsum wallboard, later in order to overcome the conductivity issue due to the presence of air, the polycarbonate and PVC panels was filled with PEG 600 and investigated experimentally. Results showed that use of polycarbonate panel filled with PEG is not suitable for light envelope for buildings but PVC panels filled with PEG 600 serves this purpose. During thermal cycle test, no degradation in the thermal properties of PVC panel with PEG 600 was noticed in the 400 cycles. A numerical simulation model also validated these experimental results.

$T_{e}\left({ }^{\circ} \mathrm{C}\right)=24+8 \sin (\omega t)$

Like other organic PCMs, PEG is also subjected to low thermal conductivity and a large number of experimental and numerical studies has been carried out to enhance this property. Wang et al. [169] prepared a form stable composite by $\mathrm{SiO}_{2}$ into PEG and this composite was characterized by SEM, FTIR and DSC. PEG of molecular weight 10,000 and $\mathrm{SiO}_{2}$ composite was prepared by dissolving PEG and $\mathrm{SiO}_{2}$ in water and stirred for $12 \mathrm{~h}$. Then the mixture was heated in the oven at $100^{\circ} \mathrm{C}$ for $24 \mathrm{~h}$, followed by heating under a reduced pressure at $70^{\circ} \mathrm{C}$ for $24 \mathrm{~h}$. SEM images showed that PEG is dispersed into the network of solid $\mathrm{SiO}_{2}$, which shows the mechanical strength of the composite. Polarizing optical microscope (POM) micrographs show that $\mathrm{SiO}_{2}$ serves as supporting material and help to prevent leakage of liquid PEG. DSC graphs showed that the latent heat of $\mathrm{PEG} / \mathrm{SiO}_{2}$ composite is less and thermal conductivity is more than that of plane PEG. The thermal conductivity of solid PEG is $0.2985 \mathrm{~W} / \mathrm{m} \mathrm{K}$, while it is $0.3615 \mathrm{~W} / \mathrm{m} \mathrm{K}$ for $\mathrm{PEG} / 20 \% \mathrm{SiO}_{2}$ (w/w) which is $21 \%$ higher and 0.5124 for $\mathrm{PEG} / 50 \% \mathrm{SiO}_{2}$, which is $71.7 \%$ higher than normal PEG. More studies based on PEG/SiO 2 composite can be found in Refs. [170-174].

The blends of PEG and fatty acids have also been studied in the past to obtain the desired range of melting temperature and latent heat. It has been possible to obtain a homogeneous PEG/fatty acid blend by mixing both materials in liquid state follow by subsequent freezing. An experimental study carried out by Pielichowski and Flejtuch [175] indicated that the melting range of such blend lies between 30 and $72{ }^{\circ} \mathrm{C}$. They investigated the series of blends of PEG with capric, lauric, myristic, palmitic, and stearic acid of different molecular weights as thermal energy storage material. Their latent heat of fusion was observed between 168 and $208 \mathrm{~kJ} / \mathrm{kg}$, which is higher than that of pure fatty acid, and PEG. In their 
further research Pielichowska et al. [176] investigated the thermal properties of blend of PEG 10,000 with lauric acid and stearic acid. The results revealed that the crystallinity of PEG/lauric acid was $52 \%$ and PEG/stearic acid $43 \%$. FT-IR images confirm the presence of hydrogen bonds in blend, both in liquid and solid state that defines their synergies. During phase change process, a synergistic effect was observed due to formation and decay of hydrogen bonding. In the similar studies done by Pielichowski and Flejtuch [177], Flejtuch [178], and Pielichowski and Flejtuch [179], the blend of PEG of different grades and fatty acids were prepared and tested for their thermal reliability as energy storage materials and was found that these materials are potential materials to be used as TES.

\subsection{Bio-based PCMs}

Bio-based PCM is a new category of organic PCMs and are obtained from underused raw materials, such as soybean oils, coconut oils, palm oils and beef tallow. Compared to organic PCMs, they possess higher latent heat, better chemical stability, are less flammable and remain stable for thousands of melting/ freezing cycels without oxidation. They have the capability to be manufactured such that their melting point can be varied in the temperature range of -22.77 and $77.83^{\circ} \mathrm{C}$ so that can be used in a variety of applications, also, they offer excellent capability for microencapsulation [180]. However, like other organic PCMs, bio-based PCMs also suffer from low thermal conductivity and leakage problem [181]. Bio-based PCMs are required to be incorporated into porous materials, such as gypsum wallboard, concrete, and others [182]. Jeong et al. [183] used xGnP for improving the thermal conductivity of bio-based PCM which contained soybean oils, coconut oils, and beef tallow and prepared a form stable material using vacuum impregnation method. They found a hike of $375 \%$ in thermal conductivity of bio-based PCM compared to bio-PCM at the cost of $25 \%$ reduction in latent heat. Subsequently, Yu et al. [184] prepared a bio-based PCM composite with $\mathrm{xGnP}$ and $\mathrm{CNT}$ and performed the thermal evaluation test and observed 336\% hike in thermal conductivity of bio-based PCM with XGnP 5.0 wt\%. TGA curves showed that both composite are thermally stable and a slight decrease in latent heat was seen. Very recently, Jeong et al. [185] adopted the vacuum impregnation method to prepare the bio-based PCM with boron nitride. A hike of $477 \%$ in thermal conductivity was measured and TGA showed the good thermal stability in composite.

Organic PCMs are generally considered as a low $\left(-30\right.$ to $80^{\circ} \mathrm{C}$ ) and medium $\left(90-227^{\circ} \mathrm{C}\right)$ melting point materials and possess the characteristics of congruent melting. In comparison to inorganic materials, they exhibit better thermal and chemical stability, even after high number of thermal cycles. They possess high latent heat per unit weight $(120-270 \mathrm{~kJ} / \mathrm{kg})$, low vapor pressure and exhibit little or no subcooling. While, inorganic PCMs require nucleating and thickening agents to minimize the subcooling and they are highly reactive to metal materials. These properties of organic PCMs make them appropriate for buildings and low and moderate temperature solar energy collectors. Apart from numerous advantages, organic PCMs suffer from low thermal conductivity $(0.15-0.35 \mathrm{~W} / \mathrm{m} \mathrm{K})$, high volume change (up to $20 \%$ ) during phase transition and they are flammable. Significant efforts have been made in the past to mitigate these shortcomings. For example, the dispersion of nano metal particles and insertion of metal matrix have been found a successful way to enhance the thermal conductivity of materials, which is discussed in detail in Section 4. Being a new category of materials, bio-based PCM have not been explored much. It has been seen that organic PCMs have their largest market in Europe while America is the largest market for inorganic and Bio-pased PCMs.

\section{Techniques to improve thermal conductivity of organic PCMs}

An organic phase change materials has a well-known drawback of having low thermal conductivity, Tables 1-4, which substantially limits the heat transfer rate during phase transition. Despite of the high energy density of organic PCMs, the slow heat transfer rate during phase change process, limits their applicability in many domestic and commercial applications. A large number of research articles have been published in the last two decades, reporting the enhanced thermal conductivity of these materials by various means, such as dispersion of high conductivity solid particles (micro/nano size) in the PCM [5], insertion of metal matrices [5,186], chunks of metal (stainless steel and copper) pieces [187], carbon fibers [188,189], and impregnation of porous graphite matrix in the PCM [187,190-192]. Jegadheeswaran and Pohekar [193] presented a detailed review on performance enhancement in latent heat thermal storage system. They discussed the various techniques such as impregnation of porous materials, dispersion of high conductivity particles, placement of metal structures, and use of high conductivity and low-density materials to enhance the thermal conductivity of PCM. A nano composite of graphene and 1-octadecanol (stearyl alcohol) was prepared by Yavari et al. [194] and thermal conductivity was investigated as a function of grapheme content. They observed the 2.5 times high conductivity of composite by the addition of $4 \%$ (by weight) graphene at the loss of $15.4 \%$ heat of fusion. Cui et al. [195] added the carbon nanofiber (CNF) and carbon nanotube (CNT) in the PCM (soya wax and paraffin wax) and observed that addition of both CNF and CNT increases the thermal conductivity of base PCM. A detailed review of studies regarding the thermal conductivity enhancement can be found in $[11,196]$. In the past graphite has been extensively used as heat transfer enhancer due to its high thermal conductivity. [4,130,197-201]. Fan et al. [202] investigated the effect of carbon nanofillers (CNT, CNF, and GNP) on thermal conductivity of paraffin based PCM by hot wire method. The concentrations were varied from $1 \%$ to $5 \%$ at an increment of $1 \%$ and found that the GNP enhanced the thermal conductivity most, approx. $164 \%$ at the loading of $5 \% \mathrm{w} / \mathrm{w}$. $\mathrm{Li}$ [203] prepared a composite of paraffin and nano graphite (NG) and reported the high thermal conductivity of this composite. Nano graphite of particle diameter $35 \mathrm{~nm}$ was added to paraffin in $1 \%, 4 \%, 7 \%$, and $10 \% \mathrm{w} / \mathrm{w}$ at $60^{\circ} \mathrm{C}$. The thermal conductivity of paraffin was measured $0.1264 \mathrm{~W} / \mathrm{m} \mathrm{K}$ and the conductivity of the composite PCM were measured to be 2.89 times and 7.41 times higher for $1 \%$ and $10 \%$ NG respectively. Nano graphite in different forms has been added to the numerous organic PCMs to enhance their thermal conductivity [202,204-208,181,209211].

Review of the experimental and numerical work reveals that the placement of fixed structure (metal matrix and fins) and dispersion of micro/nano solid particles of metals such as copper, aluminum, nickel, stainless steel and carbon nano fiber and their oxides have been primarily in use as thermal conductivity enhancer with negligible change in melting point of PCM. Nano particles are preferred over the micro sized particles because of their properties to behave like fluid and avoid the clogging during flow in pipes. Although high-thermal conductivity fillers can enhance the thermal conductivity of organic PCMs, the amount of fillers are required to be minimum in order to preserve a high energy density. Foams of copper, nickel, aluminum and other metals have reported the enhanced thermal conductivity of organic PCMs but the solid thermal conductivity of foam struts limits this enhancement. Fillers such as CNFs, CNTs, graphene, and graphene flakes possess

\section{Link to Full-Text Articles :}

\section{http://www.sciencedirect.com/science/article/pii/S0196890415000989}

